\title{
PRODUTIVIDADE E ESTADO NUTRICIONAL DO QUIABEIRO EM FUNÇÃO DA DENSIDADE POPULACIONAL E DO BIOFERTILIZANTE SUÍNO ( $\left.{ }^{1}\right)$
}

\author{
MARIA APARECIDA NOGUEIRA SEDIYAMA $\left({ }^{2 *}\right)$; MARLEI ROSA DOS SANTOS $\left({ }^{2}\right)$; \\ SANZIO MOLLICA VIDIGAL $\left({ }^{2}\right)$; LUÍS TARCÍSIO SALGADO $\left({ }^{3}\right)$; \\ MARINALVA WOODS PEDROSA $\left({ }^{4}\right)$; LUCIANO LUÍS JACOB $\left({ }^{5}\right)$
}

\begin{abstract}
RESUMO
Este trabalho teve como objetivo avaliar a produtividade e o estado nutricional do quiabeiro 'Santa Cruz', cultivado em sistema orgânico, em função de populações de plantas e doses de biofertilizante suíno. O experimento foi realizado na Fazenda Experimental da EPAMIG, em Oratórios (MG), no período de 16/10/2007 a 22/2/2008. O delineamento foi em blocos casualizados, com quatro repetições, no esquema fatorial $2 \times 5$, sendo duas populações de plantas e cinco doses de biofertilizante, obtido pela

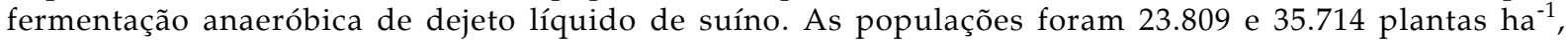
obtidas no espaçamento de 1,4 x 0,30 m com uma planta por cova e 1,4 x 0,40 m com duas plantas por cova. As doses de biofertilizante foram: $0 ; 6 ; 12 ; 24$ e $48 \mathrm{~m}^{3} \mathrm{ha}^{-1}$, sendo $80 \%$ aplicado no sulco de plantio, 15 dias antes do transplante, e 20\% em cobertura, aos 30 dias após o transplante das mudas. Avaliaramse teor foliar de nutrientes, índice SPAD, altura de plantas, número de hastes e produção de frutos comerciais e não comerciais. A aplicação do biofertilizante suíno proporcionou plantas com bom estado nutricional. O índice SPAD correlacionou positivamente com teores foliares de $\mathrm{N}$, sendo as maiores concentrações obtidas nas maiores doses de biofertilizante, especialmente na menor população de plantas. O número e a produção de frutos comerciais por planta foram maiores quando se utilizou menor população de plantas. A maior produtividade obtida na população de 35.714 plantas ha ${ }^{-1}$ foi $31,23 \mathrm{t}^{-1}$ e na população de 23.809 plantas ha ${ }^{-1}$ foi $21,90 \mathrm{t} \mathrm{ha}^{-1}$, ambas alcançadas com a maior dose de biofertilizante aplicada. A maior produtividade comercial de frutos de quiabo foi obtida na maior população de plantas.
\end{abstract}

Palavras-chave: Abelmoschus esculentus, densidade de plantio, nutrição de plantas, adubação orgânica.

( $\left.{ }^{1}\right)$ Recebido para publicação em 19 de junho de 2008 e aceito em 14 de maio de 2009.

( $\left.{ }^{2}\right)$ EPAMIG/Centro Tecnológico da Zona da Mata, Caixa Postal 216, 36570-000 Viçosa (MG), E-mail: marians@epamig.ufv.br $\left(^{*}\right)$ Autora correspondente; marleirs@yahoo.com.br, sanziomv@epamig.br

$\left(^{3}\right)$ EMBRAPA/EPAMIG/Centro Tecnológico da Zona da Mata, Caixa Postal 216, 36570-000 Viçosa (MG). E-mail: lsalgado@epamig.ufv.br

$\left({ }^{4}\right)$ EPAMIG/Centro Tecnológico do Sul de Minas, Fazenda Experimental Risoleta Neves, Campus Ctan/UFSJ, 36300-000 São João del Rei (MG). E-mail: mwoodsp@yahoo.com.br

$\left(^{5}\right)$ EPAMIG/Centro Tecnológico da Zona da Mata, Fazenda Experimental Vale do Piranga, 35430-970 Oratórios (MG). E-mail: lucianoepamig@yahoo.com.br 


\title{
ABSTRACT \\ EFFECTS OF PLANT POPULATION AND SWINE BIOFERTILIZER APPLICATION ON YIELD AND NUTRIENT CONTENT OF OKRA
}

\begin{abstract}
The objective of this work was to evaluate yield and nutritional status of organically cultivated Santa Cruz okra as a function of planting densities and doses of swine biofertilizer. The experiment was carried out at the EPAMIG Experimental Farm, in Oratorios-MG, Brazil, from 16/10/2007 to 22/02/2008. The experiment was arranged in randomized blocks, with four replications, in a $2 \times 5$ factorial, with two plant populations and five doses of biofertilizer obtained by the fermentation of liquid swine waste. The two populations were 23809 and 35714 plants.ha $^{-1}$, obtained in the $1.4 \times 0.30 \mathrm{~m}$ spacing with a plant per hole and $1.4 \times 0.40 \mathrm{~m}$ with two plants per hole. Biofertilizer doses were: $0 ; 6 ; 12 ; 24$ and $_{48} \mathrm{~m}^{3} . \mathrm{ha}^{-1}$, with $80 \%$ applied in furrow 15 days before transplantation and $20 \%$ top-dressing at 30 days after seedling transplantation. The characteristics evaluated included nutrient leaf content, SPAD index, plant height, number of stems and production of commercial and non-commercial fruits. The use o the swine biofertilizer gave plants with a good nutritional status. The SPAD index correlated positively with N leaf content, with the highest concentrations at the highest doses of the swine biofertilizer, mainly in the smallest plant population. The number and commercial fruit production per plant were larger when a smaller plant population was used. The highest yield achieved in the population of 35714 plants ha $^{-1}$ was 31.23 ton ha- ${ }^{-1}$, and in the population of 23809 plant.ha $^{-1}$ was 21.9 ton ha ${ }^{-1}$, both at the highest dose of biofertilizer. The highest commercial yield of okra fruits was obtained with the largest plant population.
\end{abstract}

Key words: Abelmoschus esculentus, plant density, nutrient concentration, organic fertilizer.

\section{INTRODUÇÃO}

O quiabo é uma hortaliça muito popular e muito apreciada pela população brasileira e ocupa lugar de destaque nesse setor em Minas Gerais, dado ao volume comercializado e ao valor da produção em determinadas épocas do ano. As temperaturas médias apropriadas para seu cultivo estão na faixa de 21,1 a $29,4{ }^{\circ} \mathrm{C}$, com a média das máximas em $35^{\circ} \mathrm{C}$ e a média das mínimas em $18,3^{\circ} \mathrm{C}$. Assim, o quiabeiro é uma das hortaliças mais exigentes em calor (CAMARGO, 1981, citado por SONNENBERg e Silva, 2002).

O quiabeiro é uma espécie potencialmente importante face a sua diversificação de uso como fonte de óleo e proteínas, como fonte de polpa de papel e combustível ou biomassa e como alimento animal (MARTIN, 1983). A cultura é muito apropriada à agricultura familiar, especialmente, pelo elevado número de serviços gastos com mão-de-obra nas operações de colheita, classificação e embalagem, além da precocidade na produção e período relativamente longo de colheita e boa alternativa de renda para o pequeno agricultor (Filgueira, 2000).

O espaçamento utilizado para o cultivo do quiabeiro varia com o sistema de condução e interesse do produtor, existindo recomendações de altas e baixas densidades populacionais, tais como: $90 \times 23$ $\mathrm{cm}, 100 \times(20-50) \mathrm{cm}$ e $150 \times 50 \mathrm{~cm}$, sendo a última com duas plantas por cova (Zanin e Кімото, 1980; Kahn et al., 2003; Setubal et al., 2004). O uso do espaçamento adequado é muito importante por exercer influência na floração, no número de hastes produtivas, na produção por planta e na produtividade da cultura (SEtubal et al., 2004), que pode ser superior a $15.000 \mathrm{~kg} \mathrm{ha}^{-1}$ (SiLva et al., 2007).

O quiabeiro possui bom desenvolvimento vegetativo e produtivo no sistema orgânico, alcançando qualidade adequada às exigências do mercado (SouzA, 1999). A cultura, normalmente, demanda altas doses de adubação orgânica, o que é de fundamental importância para nutrição adequada das plantas, qualidade dos frutos e melhoria na produtividade com menor ou nenhum uso de fertilizantes minerais nitrogenados. A adubação orgânica contribui de forma decisiva para a melhoria das características do solo, podendo inclusive reduzir o custo de produção da cultura, pois o insumo que mais onera o custo de produção do quiabeiro é o adubo mineral usado no plantio e na cobertura. No entanto, deve-se evitar o uso excessivo de adubos orgânicos o que pode acarretar desenvolvimento vegetativo exuberante, dificultando as colheitas e o controle fitossanitário, entre outros aspectos (TRANI et al., 2008).

Em conseqüência das atividades suinícolas desenvolvidas na região do Vale do Piranga, na Zona da Mata Mineira, os dejetos de suíno são resíduos orgânicos disponíveis em grandes quantidades, tornando-se viáveis estudos que os envolvam como fonte alternativa de nutrientes, para a melhoria do sistema de produção e proteção do meio ambiente. Com este trabalho, objetivou-se avaliar a produtividade de frutos, bem como o estado nutricional do quiabeiro em função de populações de plantas e doses de biofertilizante suíno. 


\section{MATERIAL E MÉTODOS}

O experimento foi desenvolvido na Zona da Mata Mineira, em Oratórios (MG), no período de $16 / 10 / 2007$ a $22 / 2 / 2008$, situado a $500 \mathrm{~m}$ de altitude, com temperatura máxima média anual de $21,8{ }^{\circ} \mathrm{C}$ e mínima média anual de $19,5{ }^{\circ} \mathrm{C}$; a precipitação pluvial média anual é de $1.250 \mathrm{~mm}$. Segundo Köppen, o clima da região varia do tipo Cwa, tropical úmido a $\mathrm{Aw}$, semi-úmido de verões quentes e a vegetação natural de floresta tropical semidecidual ou ombrofila mista (CunHa et al., 2000).

No solo utilizado, Argissolo VermelhoAmarelo câmbico, fase terraço, textura argilosa, havia, na camada de 0 a $20 \mathrm{~cm}$, as seguintes características: $\mathrm{pH}$ (água 1:2,5) = 5,6; matéria orgânica $=8 \mathrm{~g} \mathrm{~kg}^{-1} ; \mathrm{P}($ Mehlich 1$)=3,7 \mathrm{mg} \mathrm{dm}^{-3} ; \mathrm{K}$ $=67 \mathrm{mg} \mathrm{dm}{ }^{-3} ; \mathrm{Ca}^{2+}=1,9 \mathrm{cmol}_{\mathrm{c}} \mathrm{dm}^{-3} ; \mathrm{Mg}^{2+}=0,5$ $\mathrm{cmol}_{\mathrm{c}} \mathrm{dm}^{-3} ; \mathrm{Al}^{3+}=0,0 \mathrm{cmol}_{\mathrm{c}} \mathrm{dm}^{-3} ; \mathrm{H}+\mathrm{Al}=2,48$ $\mathrm{cmol}_{\mathrm{C}} \mathrm{dm}^{-3} ; \mathrm{CTC}(\mathrm{t})=2,57 \mathrm{cmol}_{\mathrm{c}} \mathrm{dm}^{-3} ; \mathrm{CTC}(\mathrm{T})=5,05$ $\mathrm{cmol}_{\mathrm{c}} \mathrm{dm}^{-3} ; \mathrm{V}=51 \%$ e P-rem $=36,9 \mathrm{mg} \mathrm{L}^{-1}$. O preparo do solo constou de uma gradagem e abertura de sulcos de plantio.

O dejeto líquido de suíno, proveniente da lavagem das baias, foi fermentado anaerobicamente em caixas de fibra de vidro tampadas, durante 30 dias. Após a fermentação esse biofertilizante apresentou as seguintes características, em $\mathrm{g} \mathrm{L}^{-1}: \mathrm{N}=22,7 ; \mathrm{P}=15,2$; $\mathrm{K}=11,0 ; \mathrm{Ca}=17,0 ; \mathrm{Mg}=7,7 ; \mathrm{S}=3,9 ; \mathrm{C}$. org. $=2,1 \mathrm{e}$ $\mathrm{Na}=5,2$ e, em mg L ${ }^{-1}, \mathrm{Zn}=2068 ; \mathrm{Fe}=3859 ; \mathrm{Mn}=$ $176 ; \mathrm{Cu}=1166 ; \mathrm{Cr}=0,13 ; \mathrm{Ni}=0,21$ e $\mathrm{Cd}=0,01 ; \mathrm{pH}$ $\left(\mathrm{H}_{2} \mathrm{O}\right)=8,61$; densidade $=1,1 \mathrm{~g} \mathrm{~cm}^{-3}$ e $\mathrm{C} / \mathrm{N}=0,09$. Os teores totais foram determinados no extrato ácido (ácido nítrico com ácido perclórico), o $\mathrm{N}$ pelo método do Kjeldahl e o Carbono Orgânico pelo Walkley Black.

O delineamento experimental utilizado foi o de blocos casualizados, com quatro repetições, no esquema fatorial $2 \times 5$. As duas populações de plantas, 23.809 e 35.714 plantas ha ${ }^{-1}$, foram obtidas no espaçamento de $1,4 \times 0,30 \mathrm{~m}$ com uma planta por cova e $1,4 \times 0,40 \mathrm{~m}$ com duas plantas por cova respectivamente. Densidades populacionais entre 20.000 e 40.000 plantas ha ${ }^{-1}$ são mais usadas no plantio de quiabo. Maiores espaçamentos entre fileiras reduzem os problemas fitossanitários, o que é importante no sistema de produção orgânica. As doses de biofertilizante suíno foram: $0 ; 6 ; 12 ; 24$ e $48 \mathrm{~m}^{3} \mathrm{ha}^{-1}$, sendo $80 \%$ aplicado no sulco de plantio, 15 dias antes do transplante das mudas, e $20 \%$ em cobertura, aos 30 dias após o transplante, aplicados ao longo das fileiras de plantas. As parcelas constaram de quatro fileiras de plantas, e para a menor população de plantas o comprimento da parcela foi de $3,0 \mathrm{~m}$ e para a maior, de $3,2 \mathrm{~m}$. Consideraram-se úteis as 16 plantas centrais em cada parcela. A área experimental não recebeu calagem nem adubação mineral.

As mudas de quiabo, cultivar Santa Cruz, foram produzidas em bandejas de isopor com 128 células e transplantadas para o campo com 34 dias de idade. Os tratos culturais como capina e irrigação foram feitos quando necessários. Para controle de insetos foram realizadas duas aplicações com óleo de Nim (Azadirachta indica), na concentração de 1\% (v/ v) no período da tarde, para não prejudicar a polinização. O controle de oídio foi feito com aplicação de leite de vaca cru 7,5\% (v/v), quando se verificou a doença e repetiu-se uma vez por semana, quando necessário (BETIOL, 2000).

Por ocasião da primeira colheita, aos 40 dias após o transplante, avaliou-se o índice relativo de clorofila, índice SPAD (Soil Plant Analysis Development), utilizando clorofilômetro (Chlorophyll Meter SPAD-502 Minolta Co., Japão). Foram realizadas leituras em dois pontos do limbo de cinco folhas jovens totalmente expandidas no horário entre $9 \mathrm{~h}$ e 10h30min. Essas folhas foram coletadas para a análise do teor de N, P, K, Ca, Mg e S. Avaliou-se também altura das plantas e altura da inserção do primeiro fruto.

As colheitas dos frutos foram realizadas duas vezes por semana, no período de $27 / 11 / 07$ a 22/2/2008. Em cada colheita, os frutos foram colhidos a partir de $9 \mathrm{~cm}$ e classificados em comercial e não comercial, sendo computado número e massa de frutos em cada classe. Foram considerados frutos comerciais aqueles maiores que $9 \mathrm{~cm}$ e menor que $15 \mathrm{~cm}$ de comprimento, macios, retos e sem deformações, ou seja, das classes 9 e 12 (CEAGESP, 2001). Os frutos com defeitos graves, fibrosos e deformados, foram considerados não comerciais. No fim do ciclo da cultura mediu-se a altura das plantas e contouse o número de hastes produtivas por planta. Os dados obtidos foram submetidos à análise de variância utilizando-se o software SAEG (2000), com desdobramento da soma de quadrado da interação, análise de correlação de Pearson e de regressão. Para efeito de comparação entre populações foi usado o teste $F$ da análise de variância. Os modelos foram escolhidos com base na significância dos coeficientes de regressão utilizando-se o teste " $\mathrm{t}$ " e adotando-se o nível de até $5 \%$ de probabilidade. Para o teor foliar de nutrientes foram calculados as médias e o desvio-padrão. 


\section{RESULTADOS E DISCUSSÃO}

Observou-se interação significativa entre populações de plantas e doses de biofertilizante para o índice relativo de clorofila (índice SPAD) e altura do primeiro fruto, as demais características avaliadas foram influenciadas pelas doses de biofertilizante, independente da população de plantas.

O índice SPAD aumentou linearmente com o aumento das doses de biofertilizante, sendo maior na menor população de plantas, alcançando valores de 46,87 e 45,65 para 23.809 e 35.714 plantas ha $^{-1}$ respectivamente (Figura 1A). De acordo com MARCussI et al. (2004), o SPAD pode ser indicativo da concentração de nitrogênio nas folhas, auxiliando no manejo da adubação nitrogenada. $O$ índice SPAD revelou correlação, $\mathrm{r}=0,88(\mathrm{P}<0,05)$ com os teores foliares de $\mathrm{N}$, para as populações estudadas.
Os teores foliares de $\mathrm{N}$ foram maiores na menor população de plantas e aumentaram linearmente com a aplicação das doses de biofertilizante nas duas populações, alcançando os valores máximos estimados em 35,89 e $32,61 \mathrm{~g} \mathrm{~kg}^{-1}$ nas populações de 23.809 e 35.714 plantas ha ${ }^{-1}$ respectivamente (Figura 1B). Para a menor densidade populacional, os teores de $\mathrm{N}$ estimados até a dose de $23 \mathrm{~m}^{3} \mathrm{ha}^{-1}$ ficaram abaixo da faixa adequada $\left(32,6-37,1 \mathrm{~g} \mathrm{~kg}^{-1}\right)$, segundo Malavolta (1987) e, a partir daí, os teores permaneceram dentro da faixa. Já para a maior população, os teores de $\mathrm{N}$ ficaram dentro da faixa adequada, segundo Malavolta (1987), apenas na maior dose de biofertilizante e abaixo da faixa adequada de 35-50 $\mathrm{g} \mathrm{kg}^{-1}$, recomendada por TRANI e RAIJ (1996), para todas as doses, provavelmente, pelo efeito de competição entre as plantas.
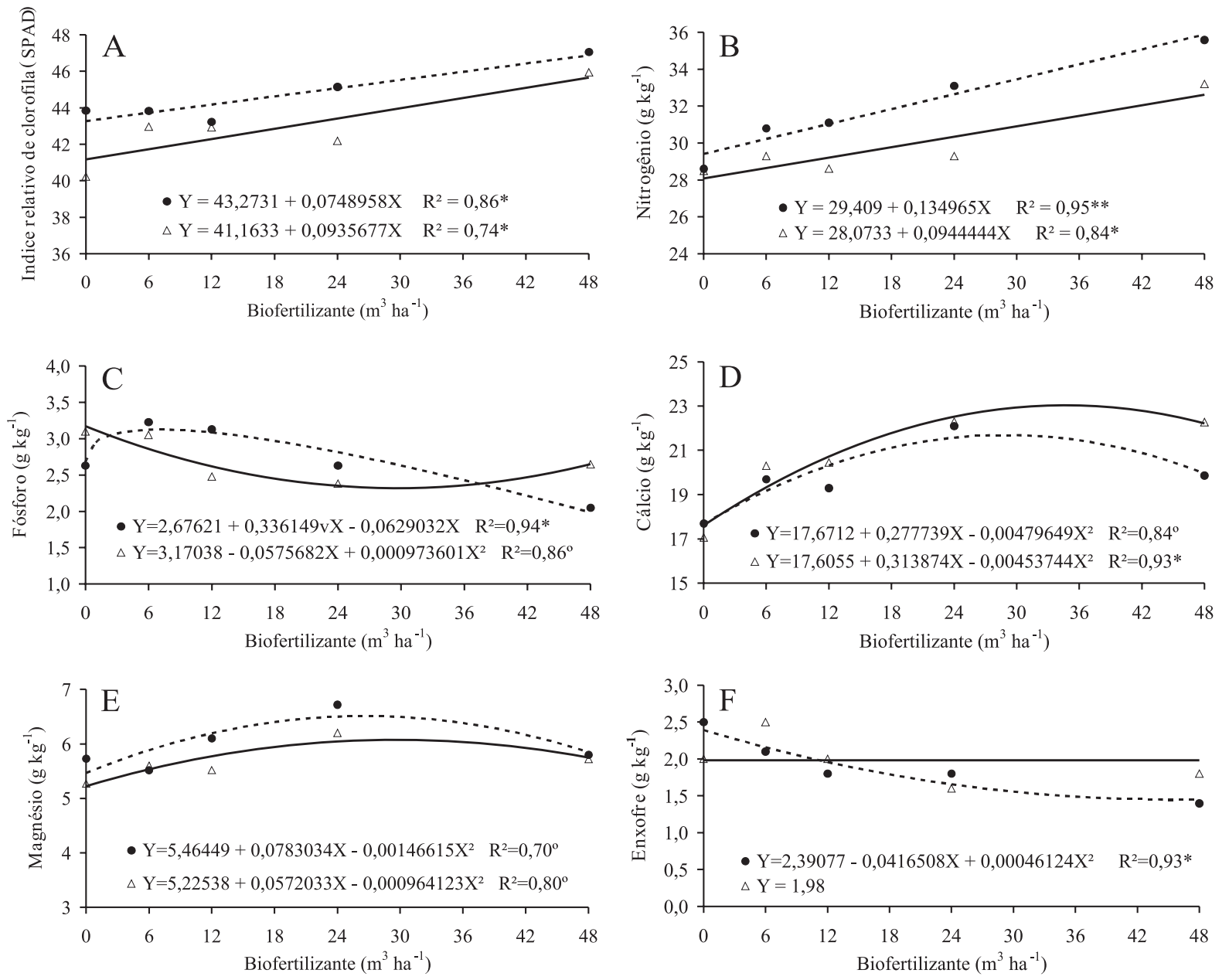

Figura 1. Índice relativo de clorofila (A) e teores de nitrogênio (B), fósforo (C), cálcio (D), magnésio (E) e enxofre (F) em folhas de quiabeiro, cultivar Santa Cruz, em função de densidades populacionais: 23.809 plantas ha $^{-1}(\bullet)$ e 35.714 plantas ha ${ }^{-1}(\Delta)$ e doses de biofertilizante suíno. Oratórios (MG), 2008.

o,, ,** Significativo a $10 \%, 5 \%$ e $1 \%$ de probabilidade pelo teste $\mathrm{t}$ respectivamente. 
Os teores foliares de $\mathrm{P}$ não diferiram significativamente entre as populações, mas reduziram com o aumento das doses de biofertilizante. Os valores estimados a partir das doses de 17 e $4 \mathrm{~m}^{3}$ ha $^{-1}$ de biofertilizante, respectivamente, para a menor e maior população de plantas, ficaram abaixo de 3,0 $\mathrm{g} \mathrm{kg}^{-1}$ (Figura 1C), ou seja, abaixo da faixa adequada (3,0-5,0 $\left.\mathrm{g} \mathrm{kg}^{-1}\right)$, segundo Malavolta (1987) e Trani e RAIJ (1996). A redução nos teores foliares de P, com aumento da aplicação de doses de $\mathrm{N}$, foi observada por MAJUnBu et al. (1986) para o quiabeiro.

$\mathrm{O}$ teor foliar de $\mathrm{K}$ foi maior na menor população de plantas, não sendo influenciado pelas doses de biofertilizante, nas duas populações, cujos valores médios iguais a 25,14 e 23,80 $\mathrm{g} \mathrm{kg}^{-1}$ foram estimados para a menor e maior população respectivamente. Esses teores ficaram acima da faixa adequada para o quiabeiro (10,5-20 $\left.\mathrm{g} \mathrm{kg}^{-1}\right)$, de acordo com Malavolta (1987) e dentro da faixa (25-40 $\mathrm{g} \mathrm{kg}^{-1}$ ) apenas para a menor população (TRANI e RAIJ, 1996).

Não houve diferença entre as populações de plantas para os teores foliares de Ca. No entanto, os teores máximos, iguais a 21,69 e 23,03 $\mathrm{g} \mathrm{kg}^{-1}$, foram estimados com a aplicação de 29 e $35 \mathrm{~m}^{3} \mathrm{ha}^{-1}$ de biofertilizante para as populações de 23.809 e 35.714 plantas ha ${ }^{-1}$, respectivamente (Figura 1D), os quais ficaram dentro da faixa considerada adequada $(16,0-$ $37,3 \mathrm{~g} \mathrm{~kg}^{-1}$ ) por Malavolta (1987) e abaixo da faixa registrada por TRANI e RAIJ (1996), que é de 35-45 g $\mathrm{kg}^{-1}$. Para os teores foliares de $\mathrm{Mg}$, também não houve diferença entre as populações de plantas, sendo os teores máximos, iguais a 6,51 e $6,07 \mathrm{~g} \mathrm{~kg}^{-1}$, estimados com a aplicação de 27 e $30 \mathrm{~m}^{3} \mathrm{ha}^{-1}$ de biofertilizante para a menor e maior população, respectivamente (Figura 1E) e ficaram dentro das faixas adequadas, que são de 2,8-8,6 $\mathrm{g} \mathrm{kg}^{-1}$ e $6-9 \mathrm{~g} \mathrm{~kg}^{-1}$ conforme Malavolta (1987) e Trani e Raij (1996), respectivamente.

Semelhante ao ocorrido com os teores foliares de $\mathrm{P}$, os teores foliares de $\mathrm{S}$ não diferiram significativamente entre as populações de plantas, reduzindo com o aumento das doses de biofertilizante para a população de 23.809 plantas ha-1 de $2,39 \mathrm{~g} \mathrm{~kg}^{-1}$ para $1,45 \mathrm{~g} \mathrm{~kg}^{-1} \mathrm{e}$, para a população de 35.714 plantas $\mathrm{ha}^{-1}$, o teor médio estimado foi igual a $1,98 \mathrm{~g} \mathrm{~kg}^{-1}$ (Figura 1F). Os teores foliares de $\mathrm{S}$ obtidos nas duas populações ficaram abaixo da faixa adequada $(2,5-4,0$ $\mathrm{g} \mathrm{kg}^{-1}$ ) para o quiabeiro (Malavolta, 1987; TRANI e RAIJ, 1996).

As alturas máximas de plantas, no início da colheita, foram de 52,99 e $54,49 \mathrm{~cm}$ para a menor e maior população, estimadas com as doses de 36,89 e $48,00 \mathrm{~m}^{3} \mathrm{ha}^{-1}$ de biofertilizante, respectivamente (Figura 2A). Na altura das plantas no início da colheita constatou-se correlação, $r=0,95$ e $0,92(P<$ $0,05)$ com a produção de frutos, para a menor e maior população de plantas respectivamente. As alturas máximas de inserção do primeiro fruto, 15,96 a 18,09 $\mathrm{cm}$, foram estimadas com 32,63 e $24,99 \mathrm{~m}^{3} \mathrm{ha}^{-1}$ de biofertilizante, para as mesmas populações respectivamente (Figura 2B). As maiores alturas de inserção do primeiro fruto foram obtidas na maior população de plantas, com exceção das doses zero e $48 \mathrm{~m}^{3} \mathrm{ha}^{-1}$.

O número máximo de hastes produtivas por planta foi obtido na maior população de plantas $(3,25$ hastes) e estimado com a dose de $32,90 \mathrm{~m}^{3} \mathrm{ha}^{-1}$, enquanto o máximo obtido na menor população $(3,12$ hastes) foi estimado com a dose de $29,73 \mathrm{~m}^{3} \mathrm{ha}^{-1}$ (Figura 2C). O número de hastes produtivas correlacionou-se positivamente, $r=0,91(\mathrm{P}<0,05) \mathrm{com}$ a produtividade por planta na menor população, mas não correlacionou na maior população, ou seja, uma população menor de plantas proporcionou maior número de hastes produtivas e maior produtividade (Figura 3B). Setubal et al. (2004) trabalhando com a cv. Amarelinho, encontrou em população de 11.111 plantas $\mathrm{ha}^{-1}$, maior número de flores por planta em função do aumento de hastes produtivas.

A maior altura das plantas no fim do ciclo $(226,38 \mathrm{~cm})$ foi alcançada na maior dose de biofertilizante aplicada $\left(48 \mathrm{~m}^{3} \mathrm{ha}^{-1}\right)$ para a maior densidade populacional. Quando se usou menor densidade a altura máxima $(224,80 \mathrm{~cm})$ foi estimada com a dose de $36,91 \mathrm{~m}^{3} \mathrm{ha}^{-1}$ de biofertilizante (Figura 2D). A altura das plantas no fim do período de colheita revelou correlação, $\mathrm{r}=0,93$ e $0,95(\mathrm{P}<0,05)$ com a produção de frutos, para as densidades populacionais de 23.809 e 35.714 plantas ha $^{-1}$ respectivamente.

O número e a produção de frutos comerciais por planta foram maiores quando se utilizou menor população de plantas (Figura 3A,B). Nas duas populações estudadas, o maior número de frutos comerciais foi obtido na maior dose de biofertilizante $\left(48 \mathrm{~m}^{3} \mathrm{ha}^{-1}\right)$, sendo 45,09 e 42,76 frutos por planta para a menor e a maior população respectivamente. As maiores produções de frutos comerciais foram de 942,20 e 874,68 g planta $^{-1}$ nas populações de 23.809 e 35.714 plantas ha ${ }^{-1}$ respectivamente. Relacionando a altura da planta e o número de hastes produtivas com os componentes de produção de frutos, nota-se ter havido diminuição significativa no número de frutos por planta, à medida que aumentou a população de plantas. Pode-se então inferir que esta diminuição tenha sido em decorrência apenas do decréscimo do número de hastes, uma vez que o aumento na população de plantas provocou aumento na sua altura. 

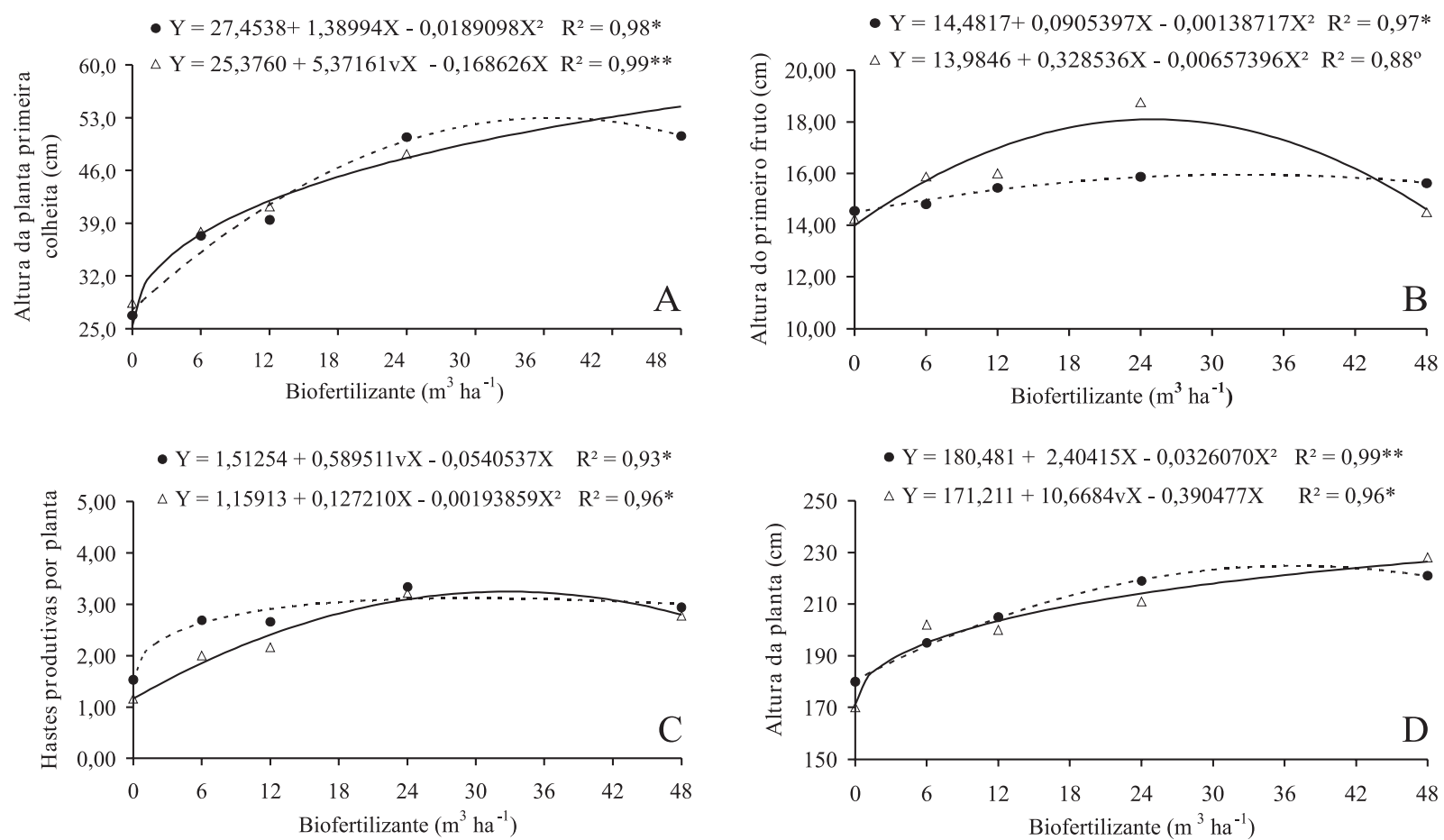

Figura 2. Altura das plantas na primeira colheita (A), altura de inserção do primeiro fruto (B), número de hastes produtivas por planta (C) e altura das plantas no final do período de colheita do quiabeiro (D), cv. Santa Cruz, em função de densidades populacionais: 23.809 plantas ha $^{-1}(\bullet)$ e 35.714 plantas ha ${ }^{-1}(\Delta)$ e doses de biofertilizante suíno. Oratórios (MG), 2008.

o, *** - Significativo a $10 \%, 5 \%$ e $1 \%$ de probabilidade pelo teste $t$ respectivamente.
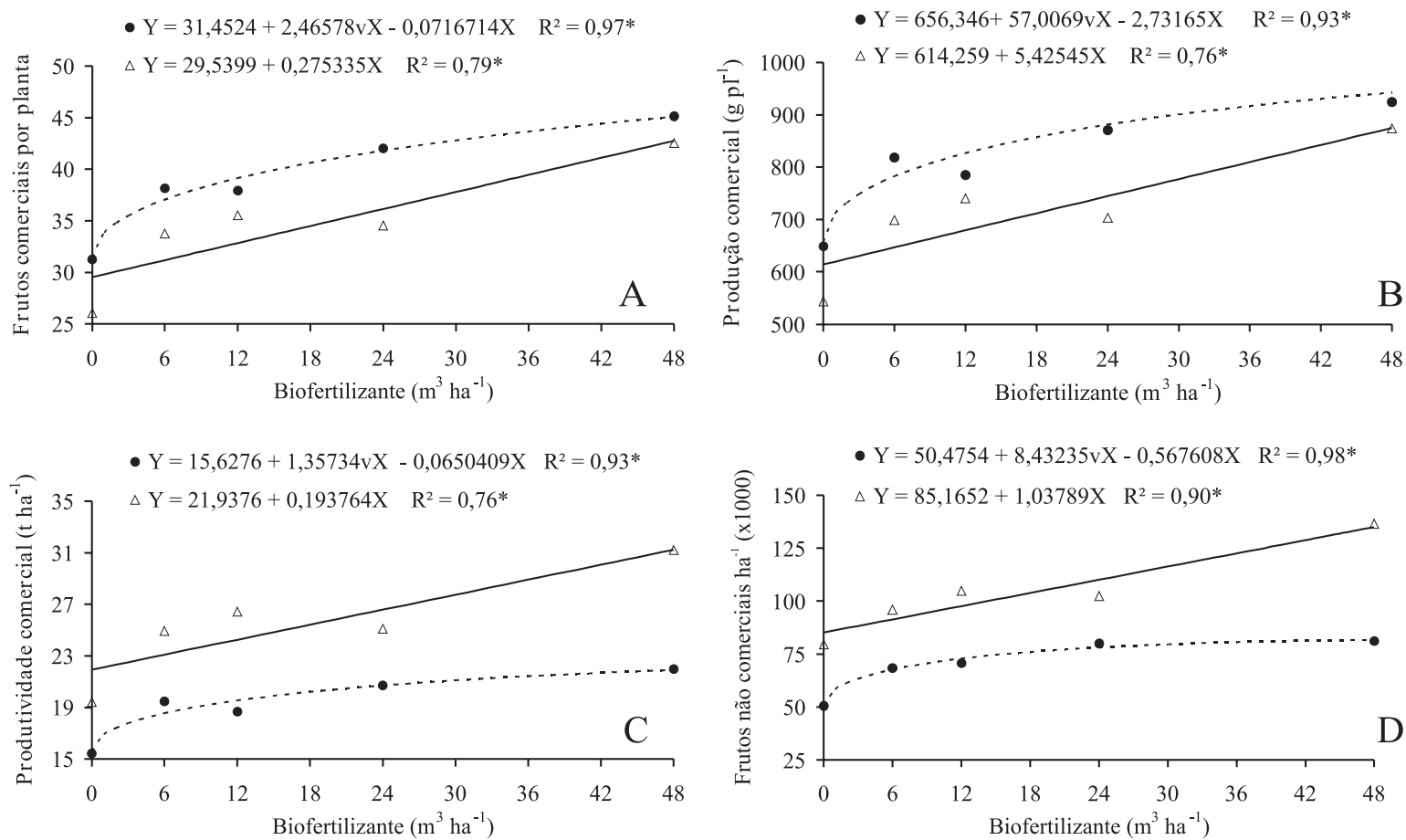

Figura 3. Número de frutos comerciais por planta (A), produção de frutos comerciais por planta (B), produtividade de frutos comerciais por hectare (C) e número de frutos não comerciais por hectare (D) de quiabeiro, cv. Santa Cruz, em função de densidades populacionais: 23.809 plantas ha ${ }^{-1}(\bullet)$ e 35.714 plantas ha ${ }^{-1}(\Delta)$ e doses de biofertilizante suíno. Oratórios (MG), 2008.

o,,${ }^{* *}$ - Significativo a $10 \%, 5 \%$ e $1 \%$ de probabilidade pelo teste $t$ respectivamente. 
Esses dados demonstram que a contribuição dos frutos formados nas ramificações, em relação ao total de frutos produzidos pela planta, é considerável na cultivar utilizada. A elevação da população de plantas provocou diminuição na produção de frutos por planta, ao mesmo tempo em que aumentou a produtividade por área. Desse modo, o aumento da população compensou a diminuição da produção de frutos por planta. Esses dados estão de acordo com os obtidos por ZANIN et al. (1980) trabalhando com a cultivar Campinas-1. Esses resultados também corroboram com SETUBAL et al. (2004), que observaram aumento no número de flores em função do maior número de ramos produtivos em menor população de plantas para a cultivar Amarelinho.

A produtividade comercial de frutos de quiabo aumentou linearmente com as doses de biofertilizante nas duas populações de plantas, sendo significativamente maior na maior população (Figura 3C). A maior produtividade obtida na população de 35.714 plantas ha ${ }^{-1}$ foi $31,23 \mathrm{t} \mathrm{ha}^{-1}$ e na população de 23.809 plantas ha ${ }^{-1}$ foi $21,90 \mathrm{t} \mathrm{ha}^{-1}$, ambas alcançadas com a maior dose de biofertilizante aplicada. Tais produtividades são superiores às obtidas por OliveIRA et al. (2003) que avaliaram o rendimento de quiabo, cultivar Santa Cruz, em função de doses de N, com colheitas realizadas a cada dois dias, durante 90 dias, e obtiveram produção máxima estimada de 16,7 tha 1 , obtida com $141 \mathrm{~kg} \mathrm{ha}^{-1}$ de $\mathrm{N}$.

$\mathrm{O} \mathrm{N}$ é o nutriente que proporciona maior resposta das plantas do quiabeiro em termos de produção de frutos (FILGUEIRA, 2000). No entanto, apesar de o teor foliar de $\mathrm{N}$ ter ficado abaixo da faixa adequada, na maior população de plantas, como já mencionado, obteve-se boa produtividade comercial, especialmente, na maior dose de biofertilizante. Nas duas populações estudadas, as produtividades obtidas ficaram acima da média para as regiões Sul e Sudeste do Brasil e, especialmente, para Minas Gerais, que é de 15 a $20 \mathrm{t} \mathrm{ha}^{-1}$ (Filgueira, 2000; Silva et al., 2007).

Observa-se que no tratamento-testemunha, a produtividade comercial alcançou $21,94 \mathrm{t} \mathrm{ha}^{-1}$ na maior população de plantas, em solo com baixos teores de matéria orgânica, fósforo e potássio disponíveis e houve ganho de até $42 \%$ com a adubação. Este fato demonstra o bom potencial de produção do quiabeiro, cultivar Santa Cruz, na região do Vale do Piranga, em que ocorre aptidão climática para a cultura. FerReira et al. (2008) observaram aumento linear da produção do quiabeiro com o aumento das doses de esterco bovino em dois anos de experimentação. A combinação de duas adubações orgânica e mineral também proporcionou aumento da produtividade.
$\mathrm{Na}$ maior população de plantas, a produtividade comercial foi $42,5 \%$ superior à obtida com a menor população. O aumento da população foi importante para o incremento de produtividade, sendo recomendável para a região.

A maior população de plantas proporcionou também maior número de frutos não comerciais por hectare (Figura 3D). Esses frutos representaram redução de 7,07 e $8,12 \%$ em relação ao total de frutos produzidos, para a menor e a maior população de plantas respectivamente.

Considerando as produtividades alcançadas nas duas populações de plantas e o sistema orgânico de produção, de modo geral, a utilização de biofertilizante como fonte de nutrientes trouxe incrementos significativos na produtividade de frutos, além de proporcionar plantas de quiabeiro com estado nutricional adequado.

\section{CONCLUSÕES}

1. A aplicação de biofertilizante suíno proporciona aumento nos teores foliares de N, Ca e $\mathrm{Mg}$ e redução nos teores de $\mathrm{P}$ e $\mathrm{S}$, sem perdas na produção por planta.

2. A maior produtividade de frutos comerciais do quiabeiro é obtida na maior população de plantas (35.714 plantas ha-1) e com $48 \mathrm{~m}^{3} \mathrm{ha}^{-1}$ de biofertilizante suíno.

\section{AGRADECIMENTOS}

À Fundação de Amparo à Pesquisa do Estado de Minas Gerais (FAPEMIG) pelo auxílio financeiro ao projeto e pelas bolsas BIPDT e Apoio Técnico.

\section{REFERÊNCIAS}

BETIOL, W. Leite de vaca cru controla doença da abobrinha. A Lavoura, v.103, n.635, p.34-35, 2000.

CEAGESP - Centro de Qualidade em Horticultura. Classificação do quiabo (Abelmoschus esculentus Moench). 2p. 2001.

CUNHA, T.J.F.; BLANCANEAUX, P.; CALDERANO FILHO, B.; CARMO, C.A.F.S.; GARCIA, N.C.P.; LIMA, E.M.B. Influência da diferenciação pedológica no desenvolvimento da seringueira no município de Oratórios, MG. Pesquisa Agropecuária Brasileira, v.35, p.145-155, 2000.

FERREIRA, J.M.; CAETANO, L.C.S.; ANDRADE, W.E.B.; VALENTINI, L.; RIBEIRO, L.J.; SILVA, M.F.S. Adubação orgânica e mineral em hortaliças no Norte Fluminense. 
Cultura do quiabeiro. Adubação orgânica e mineral em hortaliças no Norte Fluminense. Cultura do quiabeiro. Disponível em: http://www.abhorticultura.com.br/ Biblioteca/Default.asp?id=2264. Acesso em 9/5/2008.

FILGUEIRA, F.A.R. Novo manual de olericultura: agrotecnologia moderna na produção e comercialização de hortaliças. Viçosa: UFV, 2000. 402 p.

KAHN, B.A.; WU, Y.; MANESS, N.O. Densely planted okra for destructive harvest: III. Effects of nitrogen nutrition. HortScience, v.38, p.1370-1372, 2003.

MAJANBU, I.S.; OGUNLELA, V.B.; AHMED, M.K. Response of two okra (Abelmoschus esculentus L. Moench) varieties to fertilizers: Growth and nutrient concentration as influenced by nitrogen and phosphorus application. Nutrient Cycling in Agroecosystems, v.8, p.297-306, 1986.

MALAVOLTA, E. 1987. Manual de calagem e adubação das principais culturas. São Paulo: Agronômica Ceres, 1987. 496p.

MARCUSSI, F.F.N.; GODOY, L.J.G.; VILLAS BÔAS, R.L. Fertirrigação nitrogenada e potássica na cultura do pimentão baseada no acúmulo de N e P pela planta. Irriga, v.9, p.41-51, 2004.

MARTIN, F.W. Okra, potential multiple-purpose crop for the temperate zones and tropics. Economic Botanic, v.3, p.340$345,1983$.

OLIVEIRA, A. P.; ALVES, A. U.; DORNELAS, C. S. M.; SILVA, J.A.; PORTO, M. L.; ALVES, A. U. Rendimento de quiabo em função de doses de nitrogênio. Acta Scientiarum Agronomy, v.25, p.265-268, 2003.

SAEG. Sistema para Análise Estatística. Versão 8,0. Viçosa: Fundação Artur Bernardes, 2000.

SETUBAL, J.W.; ZANIN, A.C.W.; SITTOLIN, I.M. Hábito de florescimento do quiabeiro cv. Amarelinho em função da população de plantas. Horticultura Brasileira, v.22, 2004. (Suplemento CD- ROM)

SILVA, M.B.; COSTA, C.R.; COSTA, A.S.V.; PREZOTTI, L. Quiabo (Abelmoschus esculentus L.). In: 101 Culturas: manual de tecnologias agrícolas. Coordenadores: PAULA JUNIOR., T.J; VENZON, M. Belo Horizonte:EPAMIG, 2007. 800p.

SONNENBERG, P.E.; SILVA, N.F. Desenvolvimento e produção do quiabeiro em função das datas de plantio. Pesquisa Agropecuária Tropical, v. 32, n.1, p.33-37, 2002.

SOUZA, J.L. Estudos de métodos de nutrição orgânica do quiabeiro (Abelmoschus esculentus). In: CONGRESSO BRASILEIRO DE OLERICULTURA, 39., 1999, Tubarão - SC. Suplemento SOB (Resumo 375).

TRANI, P.E.; PASSOS, F.A., TEODORO, M.C.C.L.; SANTOS, V.J.; FRARE, P. Calagem e adubação para a cultura do quiabo. Disponível em <www.iac.sp.gov.br/Tecnologias/Quiabo/ Calagem_Quiabo.htm> Acesso em 9/5/2008.

TRANI, P.E.; RAIJ, B. van. Hortaliças. In: RAIJ, B. van et al. (Ed.). Recomendações de adubação e calagem para o Estado de São
Paulo. 2.ed. Campinas: Instituto Agronômico/Fundação IAC, 1996. Cap. 18, p. 157-185. (Boletim Técnico, 100)

ZANIN, A.C.W.; KIMOTO, T. Efeito da adubação e espaçamento na produção de sementes do quiabeiro. Revista Brasileira de Sementes, v.2, p.105-112, 1980. 